\title{
Análisis de la calidad de vida en el Cantón Déleg, Provincia del Cañar-Ecuador*
}

\author{
Jaimes, Edgar** \\ Orellana, René*** \\ Reiban, Miriam**** \\ González, Juan C..****
}

\section{Resumen}

El objetivo del trabajo fue analizar la calidad de vida en los sectores Bayandel, Chini, Déleg y Nueva Alianza, en el Cantón Déleg, Provincia del Cañar, Ecuador. La investigación fue descriptiva, participativa y no probabilística. Se valoraron los factores, variables y subvariables indicadoras implícitas en la calidad de vida de estas comunidades que, en los sectores medio y alto de la subcuenca, es buena ya que el valor promedio del índice de calidad de vida se ubicó en el rango de 8.769-16.384. Se concluye que el índice de calidad de vida es una herramienta eficaz para medir el nivel de vida, de allí que los resultados obtenidos serían de utilidad para el gobierno municipal, y a las mismas comunidades que habitan dichos sectores ya que coadyuvaría en la definición de políticas públicas y acciones comunitarias dirigidas a mejorar la calidad de vida de la gente que habita en ese Cantón. Se reco-

\section{Recibido: 20-04-16. Aceptado: 15-07-16}

* Se agradece al Gobierno Autónomo Descentralizado (GAD) del Cantón Déleg; a la Dirección de Investigación y Postgrado de la Universidad Católica de Cuenca (UCACUE) y al Proyecto Prometeo-SENESCYT, República del Ecuador; por el apoyo institucional y financiero dado al Dr. Edgar Jaimes y al grupo de investigación de la UCACUE, para la realización de este trabajo de investigación.

** Ingeniero Agrónomo, Universidad del Zulia; Agrólogo, ULA-CIDIAT; M. Sc. y Ph.D. en Ciencia del Suelo, UCV. Profesor Titular Jubilado del Núcleo Universitario "Rafael Rangel" (NURR); Universidad de Los Andes (ULA); Grupo de Investigación de Suelo y Agua (GISA). Venezuela. Investigador Emérito del PEII-ONCTI, 2015. E-mail: jaimes.5060@gmail.com; jaimes@ula.ve

*** Ingeniero Agrónomo; M. Sc. en Agronomía. Profesor Titular de la Unidad Académica de Agricultura, Silvicultura, Pesca y Veterinaria; UCACUE. Panamericana Norte, Km 2,5. Cuenca, Ecuador. E-mail: rorellanam@ucacue.edu.ec

**** Ingeniera Agrónoma; M. Sc. en Agronomía. Profesora Titular de la Unidad Académica de Agricultura, Silvicultura, Pesca y Veterinaria; UCACUE. Panamericana Norte, Km 2,5. Cuenca, Ecuador. E-mail: mreibanl@ucacue.edu.ec

***** Ingeniero Agrónomo; M. Sc. y Ph.D. en Agronomía. Profesor Titular de la Unidad Académica de Agricultura, Silvicultura, Pesca y Veterinaria; UCACUE. Panamericana Norte, Km 2,5. Cuenca, Ecuador. E-mail: jgonzalezr@ucacue.edu.ec 
mienda continuar con este estudio, extendiéndolo hacia otras comunidades localizadas en la Provincia del Cañar, utilizando esta metodología.

Palabras clave: Calidad de vida, desarrollo cultural, vulnerabilidad socioeconómica, estabilidad del entorno, uso de los recursos naturales

\title{
Analysis of the Life Quality in the Déleg Canton, Province of Cañar-Ecuador
}

\begin{abstract}
The objective was to analyze the life quality in Bayandel, Chini, Delek and New Alliance Nueva Alianza sectors in Déleg canton, Cañar Province, Ecuador. The research was descriptive, participatory and non-probabilistic. The factors were valued, variable and sub-variable indicators implicit in the life quality of these communities which, in the middle and upper sections of the sub-basin, is good because the average value of the index of life quality was in the range of $8,769-16,384$. It is concluded that the index of life quality is an effective way to measure the life standard, hence the results would be useful for the municipal government, and the communities that inhabit these sectors as would assist in defining public policies and community actions aimed at improving people's life quality in the Canton. It is recommended to continue this study, spreading it to other communities located in the province of Canar, using this methodology.
\end{abstract}

Keywords: Quality of life;, cultural development; socio-economic vulnerability; environmental stability; use of natural resources.

\section{Introducción}

El concepto de calidad de vida está directamente asociado al de bienestar, el cual ha sido objeto de una atención permanente en los temas del desarrollo social, económico y cultural; con el objeto de establecer un equilibrio entre la cantidad de seres humanos y los recursos disponibles y la protección del medio ambiente. El interés por la calidad de vida ha existido desde hace varias décadas; sin embargo, la aparición del concepto como tal y la preocupación por su evaluación sistemática y científica es relativamente reciente.

En realidad, el término calidad de vida comenzó a popularizarse en la década de los 60 hasta convertirse hoy en un concepto utilizado en ámbitos muy diver- sos, como salud, educación, economía, política y servicios en general, permitiendo que en los últimos diez años sea motivo de debates públicos en relación con el entorno agroecológico y ambiental y, más específicamente, con el deterioro de las condiciones de vida urbana y rural; de allí el creciente interés por conocer el bienestar humano y la preocupación por las consecuencias del deterioro socioambiental, lo cual ha motivado el interés por medir de forma adecuada, el bienestar social o buen vivir de una determinada población a través de datos objetivos, con base en diversas variables o indicadores sociales, ambientales, agroecológicos, económicos y culturales.

Estos indicadores tuvieron su propia evolución, siendo en un primer mo- 
mento referencia de las condiciones objetivas, de tipo económico y social, para en un segundo momento contemplar elementos subjetivos. De cualquier manera, el estudio de la calidad de vida constituye un terreno donde los especialistas aportan sus enfoques; por ejemplo, los ambientalistas sitúan el énfasis en el entorno agroecológico-ambiental, los economistas en parámetros como las relaciones consumo-producto, costo-beneficio o el Producto Interno Bruto; los médicos en los síntomas de las enfermedades o condiciones de la salud humana y los psicólogos o sociólogos en las necesidades humanas y su satisfacción.

Con base en lo antes indicado, es obvio que la calidad de vida es un concepto complejo y que abarca varios aspectos de la vida. Pero ¿es acaso posible decir que la calidad de vida es sólo la satisfacción de lo material y lo inmaterial? ¿Qué papel juega el entorno que rodea a toda actividad humana y que "no forma parte de su vida", simplemente porque no se le reconoce? Es que acaso los miles de niños que mueren por causa del hambre en el mundo, no son parte de nuestro entorno? Entonces es allí donde cabe preguntarse si solamente es calidad de vida la satisfacción de lo personal o de lo colectivo.

Hasta ahora sólo se habla de lo que cada uno quiere, de lo que cada uno aspira, de lo que cada uno espera, pero no se dice nada de lo que nuestros semejantes necesitan para estar bien; en ese sentido, Lovelock (2007) considera que el concepto de CV parece netamente egocéntrico, individualista, hegemónico-narcisista y que hasta atenta con los derechos humanos, pues en su afán de satisfacer necesidades individuales, la "racionali- dad" que actualmente predomina está llevando a la destrucción del planeta como única fuente de recursos y, en consecuencia, a la desaparición de la especie humana.

El objetivo de este trabajo es analizar la calidad de vida en los sectores de Bayandel, Chini, Déleg y Nueva Alianza, localizados en la subcuenca alta y media del río Déleg (Cantón Déleg), Provincia del Cañar, República del Ecuador.

La metodología de investigación fue no experimental, descriptiva e incluyó la aplicación de instrumentos de consulta directa, voluntaria e intencional, con muestreo no probabilístico; ya que dependía de la disposición de los miembros de las comunidades evaluadas para participar y contestar los cuestionarios. las técnicas de investigación fueron: la observación directa; los diálogos semi-estructurados y las entrevistas estructuradas.

Previo a la aplicación de las encuestas se dio a conocer a las personas entrevistadas un modelo de consentimiento informado individual, en un todo de acuerdo con la convención de Helsinki y los códigos de Bioética y Bioseguridad establecidos por la Secretaría Nacional de Educación Superior, Ciencia y tecnología (SENESCYT), del Ecuador.

\section{Calidad de vida: precisiones teóricas}

Para analizar y entender el concepto de calidad de vida, Contreras y Cordero (1994) propusieron un conjunto de factores y variables asociadas con la satisfacción de las necesidades fisiológicas, psicofisiológicas, culturales, sociales y de requerimiento ambiental. Pero este con- 
cepto también se refiere a una sensación existencial, como lo es la percepción que un individuo o una comunidad tiene conforme a la calidad del ambiente en el cual vive. Se indica que la actividad humana incluye muchos valores, conceptos y formas de pensar, fundamentales para sustentar la vida y dar sentido y significado a su existencia, que son aspectos de considerable importancia, pero muy difíciles de evaluar por la gran variabilidad de conceptos que ello conlleva.

Suarez, et al (2005) determinaron el impacto positivo que ha tenido la aplicación de un microcrédito para el mejoramiento en la calidad de vida en una comunidad rural de Lomas Tepemecatl, Distrito Federal, México; mediante el funcionamiento adecuado de microempresas productivas agropecuarias administradas por mujeres, obteniendo así el mejoramiento en la calidad de vida de las mujeres que viven en zonas rurales.

Así mismo, González (2012), para determinar la calidad de vida en la comunidad Ribereña del río Orinoco, específicamente en las Galderas, estado Bolívar, Venezuela, considera dos elementos de juicio; a saber: percepción global de la calidad de vida e información objetiva de elementos y situaciones que más impactan la calidad de vida del grupo.

En estas dos últimas investigaciones se empleó el modelo de evaluación propuesto por Contreras y Cordero (1994); la primera concluye que es una herramienta apropiada para el estudio integral de esquemas de desarrollo rural por su carácter multidimensional; sin embargo, la segunda investigación (González, 2012), concluye que prevalece la subjetividad, no cuenta con una descrip- ción de criterios para la evaluación de la escala de valoración de cada sub-variable, lo que le otorga debilidad metodológica, limita la posibilidad de interpretar la dependencia e interdependencia de estos en la valoración de la comunidad ya que establece igual valor promedio a todos los factores.

Por su parte, Palomba (2002), consideró que la calidad de vida de una persona o grupo familiar está referida a tres aspectos fundamentales; esto es: (a) en términos de la satisfacción experimentada por la persona con condiciones vitales; (b) como la combinación de componentes objetivos y subjetivos y (c) como la combinación de las condiciones de vida y la satisfacción personal, ponderadas por la escala de valores, aspiraciones y expectativas personales.

De acuerdo con esta reflexión, es pertinente resaltar que la calidad de vida es una propiedad integral y compleja de un entorno socio-ambiental dado que le asigna valor a un conjunto de condiciones determinantes del buen vivir de las personas que pertenecen a dicho entorno; es decir, es el carácter valorativo en una escala de comparación entre lo que es bueno o malo para una comunidad; no obstante, la cuestión no sólo queda allí, ya que dicho aspecto contiene elementos tanto objetivos como subjetivos, lo cual hace difícil determinar y definir, de manera estricta y universal, el término calidad de vida.

Según Ardila (2003: 163): "Calidad de vida es un estado de satisfacción general, derivado de la realización de las potencialidades de la persona. Posee aspectos subjetivos y aspectos objetivos. Es una sensación subjetiva de bienestar físico, psicológico y social. Incluye como 
aspectos subjetivos la intimidad, la expresión emocional, la seguridad percibida, la productividad personal y la salud objetiva. Como aspectos objetivos el bienestar material, las relaciones armónicas con el ambiente físico y social y con la comunidad, y la salud objetivamente percibida".

En este contexto, es pertinente resaltar la reflexión realizada por Córdova (2007) en el sentido de profundizar en el debate conceptual del término calidad de vida, abordando aspectos como su naturaleza: objetiva o subjetiva; su delimitación de enfoques afines; su estructura, dimensional o global; los instrumentos y las medidas más idóneas para su evaluación; toda vez que resulta imposible hacer una reflexión, medianamente completa de los problemas que atañen a la investigación de la calidad de vida, relacionando todos los parámetros que la integran.

Partiendo de este enfoque, Urbina (2012), señala que la calidad de vida representa aquella condición favorable que permite a los seres humanos vivir en armonía con lo material y espiritual desde su cosmovisión; destacando que para algunas personas la calidad de vida no es solamente la satisfacción de las necesidades reales, sino también la satisfacción de aquellas necesidades que, según el contexto en que cada persona se desarrolla, van surgiendo y se van incorporando al estilo de vida. Por ejemplo, en algunas sociedades el aspecto tecnológico está siendo tan incorporado a la cotidianidad, que tal y como se presenta en la actualidad está pasando a formar parte de las necesidades básicas de los humanos modernos; $y$, en consecuencia, a los elementos que en la vida actual pueden ser determinantes de su calidad.
En efecto, lo que se busca es una aproximación al análisis de los principales problemas actuales que atañen directamente con el estudio de la calidad de vida. Tal aproximación no puede lograrse sin una clara convicción de los límites de cada una de las disciplinas y aspectos que lo integran, ni tampoco con la hiperbolización de una vertiente en su conceptualización o medición a expensas de otra. Desde esta prospectiva, el estudio de la calidad de vida obliga a abandonar posiciones tradicionales y vislumbrar fuentes comunes de estudio.

Teniendo como referentes las reflexiones antes resumidas, es pertinente incluir en estas precisiones teóricas una serie de argumentos globales relacionados con la Complejidad, mismos que fueron formulados por Conceçiao de Almeida (2008), ya que la vida humana desde hace 10.000 años ha transcurrido inmersa en el contexto de la complejidad natural. En ese sentido, para comprender la complejidad de la naturaleza y, por extensión, el de las condiciones que determinan la calidad de vida en el contexto del planeta Tierra, o el de una comunidad local o específica, es obligante reflexionar y analizar estas Ideas-Fuerza, entre los cuales se destacan los siguientes:

2-1. Lo complejo siempre hace referencia al conjunto de elementos heterogéneos inseparablemente asociados, que presentan la relación paradójica entre lo uno y lo múltiple; valga decir, entre el individuo y su entorno social, ambiental, económico, político y cultural.

2-2. Lo complejo admite la incertidumbre, de allí que sea imprevisible, indeterminado, no lineal y metaestable. 
2-3. La complejidad de la vida se construye y mantiene por la autoorganización, propiedad que permite a los sistemas biológicos mantener, dentro de sí y su entorno, flujos de intercambio de materia, energía e información, reordenándola y transformándola en nuevos patrones de organización; de allí que esta complejidad esté marcada por lo inconcluso o inacabado, ya que siempre está en evolución, alteración o mutación.

2-4. Lo complejo es simultáneamente dependiente y autónomo, necesitando de un contexto, organizándose a partir de sí mismo, generando a la vez propiedades o procesos emergentes.

2-5. Lo complejo de la vida humana está signado por las fluctuaciones, produciendo bifurcaciones en su tránsito evolutivo, por lo que siempre estará alejado del equilibrio.

Así mismo, es conveniente hacer un análisis retrospectivo, echar un vistazo al pasado, para poner en evidencia que la visión tecnológica futurista solo es un espejismo; por el contrario, la gran solución se encuentra en las experiencias de nuestros ancestros, que parecen haber tenido mejor suerte, pues al considerar la Tierra como una hermana, solo tomaban de ella lo necesario y daban tiempo a recuperarse con el fin de garantizar la obtención de nuevos recursos para la vida.

Aquí es muy pertinente recordar la encíclica No 18 del Papa Francisco (2015) ya que integra las ideas clave previamente analizadas respecto al término de calidad de vida. En efecto, lo que señala esa encíclica gira en torno a la intensificación de los ritmos de vida y trabajo a consecuencia de la continua aceleración de los cambios de la humanidad y del planeta, derivada de estilos de vida que poco tienen que ver con el buen vivir.

Si bien esta encíclica entiende y asume que estos estilos de vida forman parte de la dinámica de los sistemas complejos, la intensificación que las actividades humanas le imponen hoy contrasta con la natural lentitud de la evolución biológica; suma al hecho de que los objetivos de ese cambio veloz y constante no necesariamente se orientan al bien común; es decir, a un desarrollo humano, sostenible e integral. En síntesis, el cambio es algo deseable, pero se vuelve preocupante cuando se convierte en deterioro ambiental porque en la práctica degrada la calidad de vida de gran parte de la humanidad.

Casi diez años antes de esta interesante reflexión papal, Lovelock (2007: 96 y 97) lo había previsto con base a criterios científicos irrefutables: “...puede que nuestra especie nunca vuelva a disfrutar del mundo exuberante y verde que existió hace tan solo cien años. Lo que está gravemente en peligro es la civilización".

Con base en estas precisiones y reflexiones teóricas, se indica a continuación el modelo aplicado para la determinación del Índice de Calidad de Vida (ICV) de las comunidades objeto de esta investigación; a saber:

$I C V=A \times B \times C \times D \times E \times F \times G$

\section{3. Índice de calidad de vida (ICV): precisiones metodológicas}

El modelo de ICV antes referido es una propuesta modificada por Jaimes, 
Carballo y Mendoza (2014), citados por Raymundo y Jaimes (2015) a partir del método definido por Contreras y Cordero (1994); consta de siete (7) factores (A, B, $C, D, E, F$ y $G$ ); veintiún (21) variables y cincuenta y tres (53) sub-variables indicadoras. Cada factor agrupa tres (03) variables y éstas a su vez engloban entre una (01) y tres (03) sub-variables indicadoras, mismas que fueron redactadas bajo la forma de Ideas-Fuerza y que se valoran de acuerdo a los baremos, indicados más abajo, los cuales sirvieron de base para las consultas realizadas a los grupos familiares que se ofrecieron voluntariamente para este estudio. En la Tabla 1 se indican estos factores y las variables implícitas en cada uno de ellos.

Tabla 1

Factores y variables para el cálculo del ICV en las áreas bajo estudio

\begin{tabular}{ll}
\hline \multicolumn{1}{c}{ Factores } & \multicolumn{1}{c}{ Variables $\left(^{*}\right)$} \\
\hline A = Fisiológico & A-1. Alimentación y nutrición \\
& A-3. Sanidad ambiental \\
\hline B = Psicofisiológico & B-4. Condiciones de la vivienda \\
& B-5. Estética ambiental \\
& B-6. Descanso y recreación \\
\hline C = Desarrollo cultural & C-7. Desarrollo de aptitudes y capacidades \\
& C-8. Participación efectiva en la comunidad \\
& C-9. Trabajo adecuado a las aptitudes de la persona \\
\hline D = Condicionamiento psicosocial & D-10. Relaciones interpersonales \\
& D-11. Seguridad individual y colectiva \\
& D-12. Estima socio-cultural y pertenencia \\
\hline E = Dependencia ecológico-ambiental & E-13. Productividad del entorno \\
& E-14. Estabilidad del entorno \\
& E-15. Criterio de uso de los recursos naturales \\
\hline F = Vulnerabilidad y riesgos & F-16. Vulnerabilidad psicofísica \\
& F-17. Vulnerabilidad social \\
& F-18. Vulnerabilidad socioeconómica \\
\hline & G-19. Ejercicio de derechos \\
& G-20. Defensa de derechos \\
& G-21. Deberes y responsabilidades \\
\hline &
\end{tabular}

Fuente: Elaboración propia.

(*) Las 53 subvariables indicadoras están insertas en las Tablas 3 a la 9

Para calificar e Interpretar los cálculos del ICV, obtenidos a través del modelo de marras, se deben utilizar los rangos del ICV que se muestran en la Tabla 2. 


\section{Tabla 2}

Valoración de los rangos del ICV y su calificación

\begin{tabular}{cc}
\hline Rangos del ICV & Calificación \\
\hline $78.125-42.251$ & Excelente \\
$42.250-16.385$ & Muy buena \\
$16.384-8.769$ & Buena \\
$8.768-2.188$ & Regular \\
$2.187-1.187$ & Mala \\
$1.186-145$ & Muy mala \\
$144-1$ & Colapso \\
\hline
\end{tabular}

Fuente: Elaboración propia.

Los modelos de encuestas (Tablas 3 a la 9) fueron los instrumentos aplicados para valorar los niveles de calidad de vida en las comunidades objeto de esta investigación; mismos que fueron aplicados a un total de ciento veinte (120) familias, distribuidas en grupos de treinta (30) en cada uno de los sectores bajo estudio. Para tales fines, se organizaron ocho giras técnicas a dichas comunidades, cinco de las cuales se realizaron entre abril-mayo-junio de $2015 \mathrm{y}$, las tres restantes, enero y febrero de 2016.

Para valorar las sub-variables indicadoras se utilizó el modelo de escalamiento tipo Likert, citado por Palella y Martins (2006), el cual consiste de una serie de frases cortas, redactadas bajo el formato de preguntas o afirmaciones; a partir de los cuales se consulta a las personas encuestadas con el propósito de obtener su respuesta mediante la elección de uno de los cinco ítems de dicha escala, para lo cual se utilizan palabras clave como las siguientes: Siempre; Casi siempre; Frecuente; Pocas y Nunca; cuyo propósito es precisar la frecuencia en que los encuestados son capaces de apreciar los niveles de acuerdo sobre tales preguntas.

En ese sentido, cada sub-variable indicadora y palabra clave, mostradas en las Tablas 3 a 9, se indican celdas (columnas) con números que están ordenados en sentido ascendente ( 1 al 5 ) o en forma descendente ( 5 al 1 ); según el sentido desfavorable (negativo) o favorable (positivo); respectivamente, en que esté redactada la dirección de la Idea-Fuerza, afirmación o juicio que represente o corresponda a las sub-variables indicadoras.

\section{Análisis de la calidad de Vida en Cantón Déleg}

A continuación se presenta la descripción del área de estudio y los resultados obtenidos del análisis de los indicadores y variables de la calidad de vida de los habitantes de los sectores Bayandel, Chini, Déleg y Nueva Alianza, en el Cantón Déleg, Provincia del Cañar, Ecuador.

\subsection{Descripción general del área de estudio}

Con base en el resumen del Plan de Desarrollo y Ordenamiento Territorial del Cantón Déleg y Actualización del Plan de Ordenamiento Territorial del Centro Urbano, realizado por la empresa CONSULCENTRO (2011), a continuación se sintetizan los aspectos más resaltantes de las características generales de dicho Cantón, a saber:

4.1.1. Paisaje. El área de estudio es poseedora de un capital ambiental muy significativo toda vez que aún cuenta 


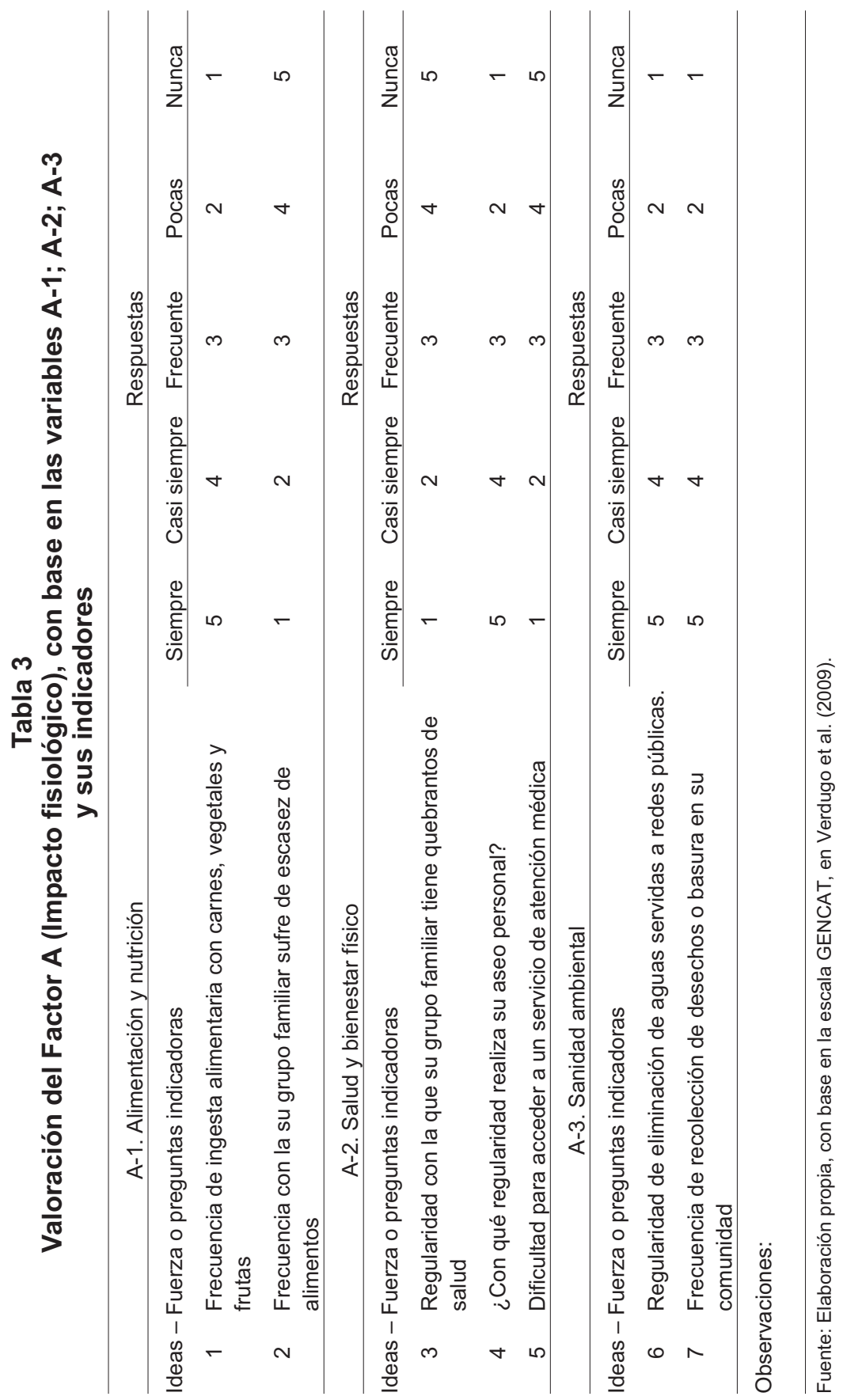




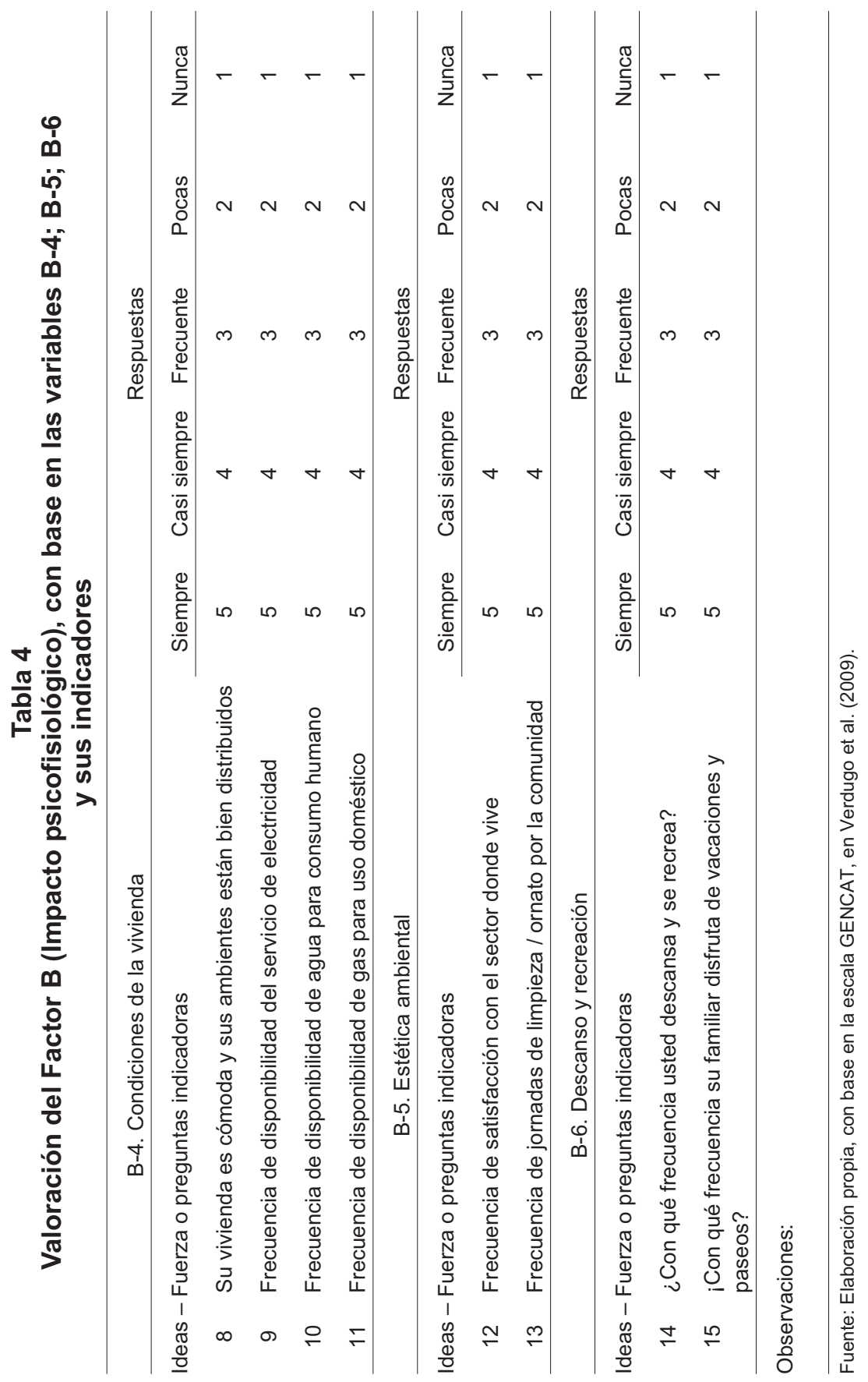




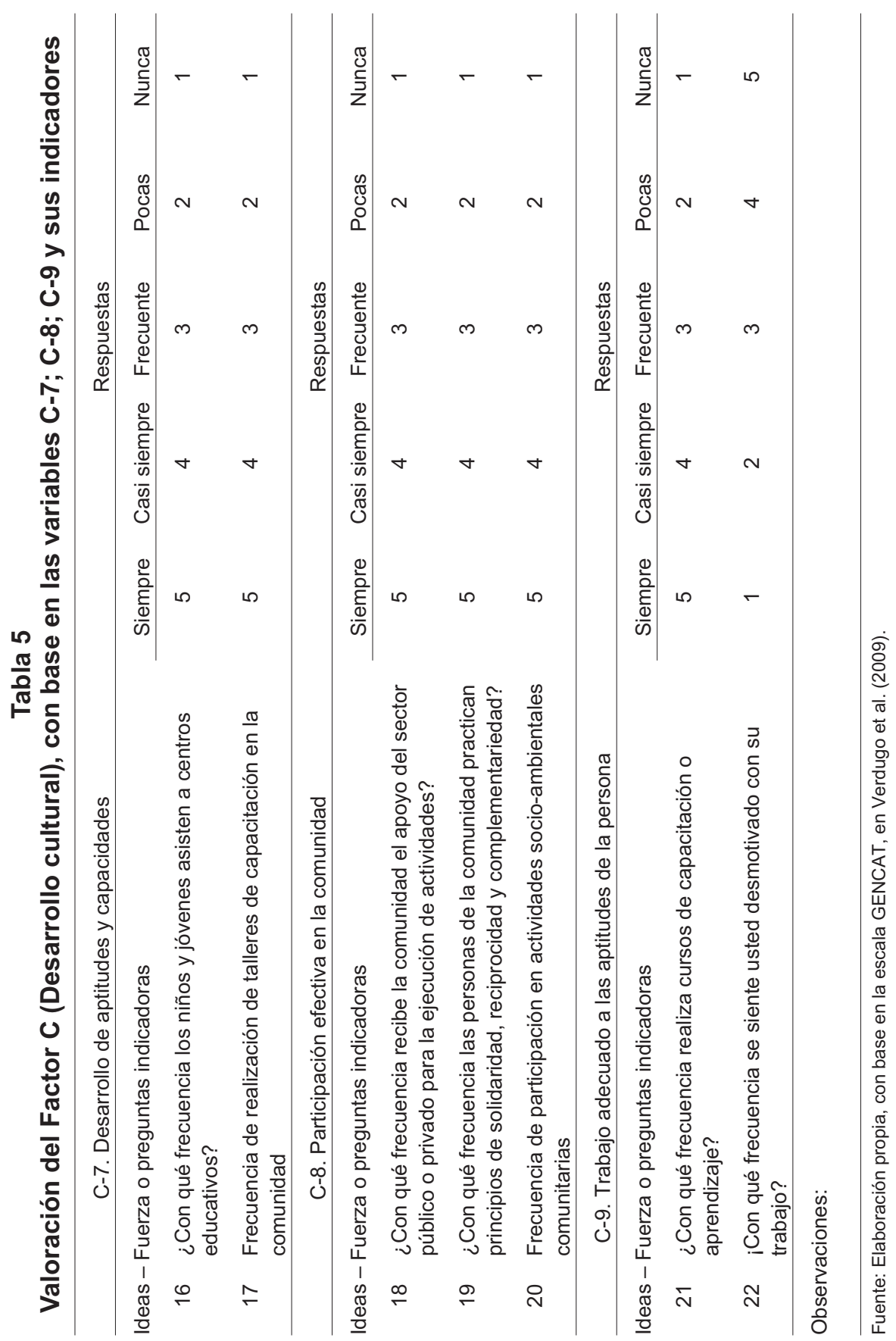




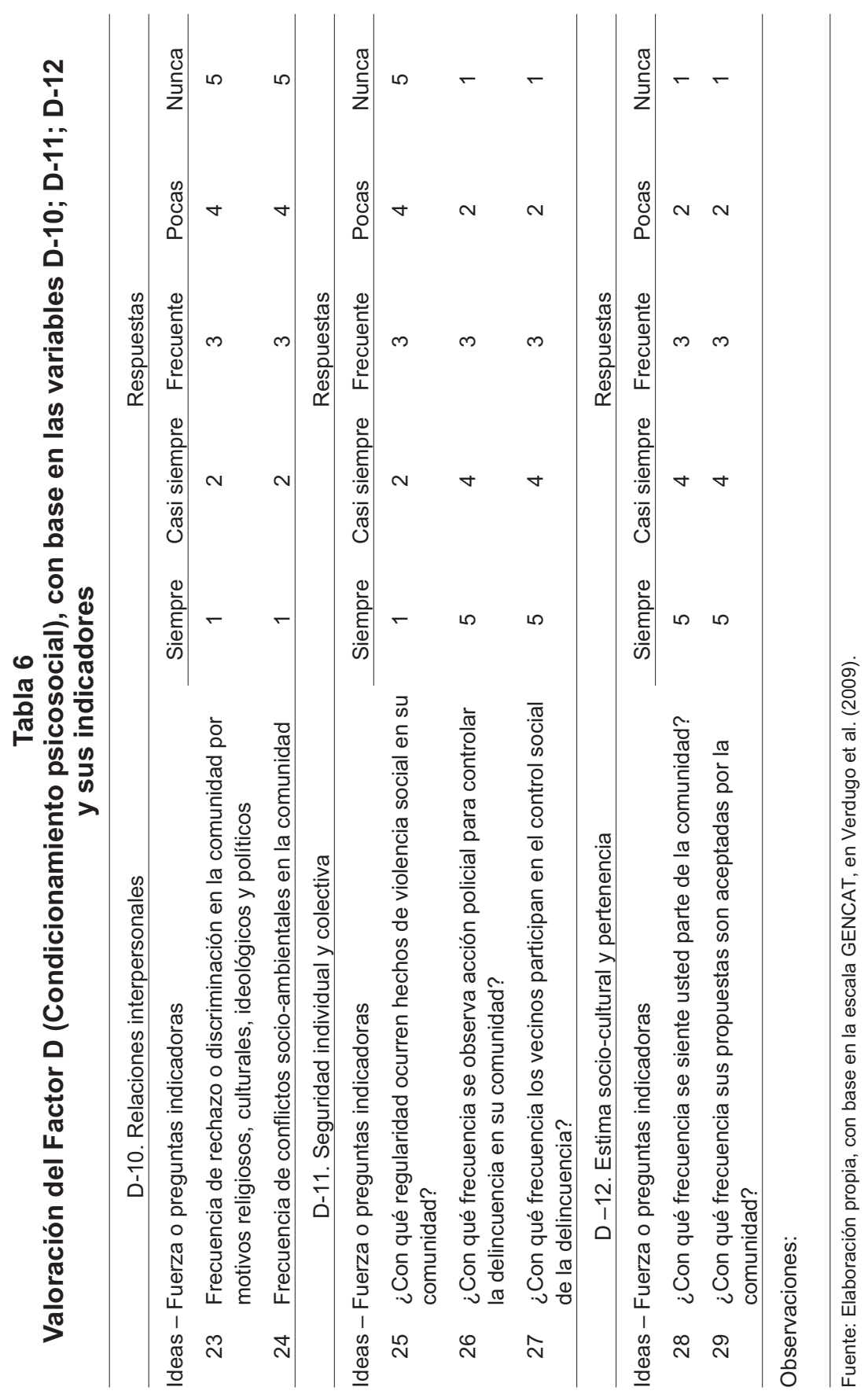




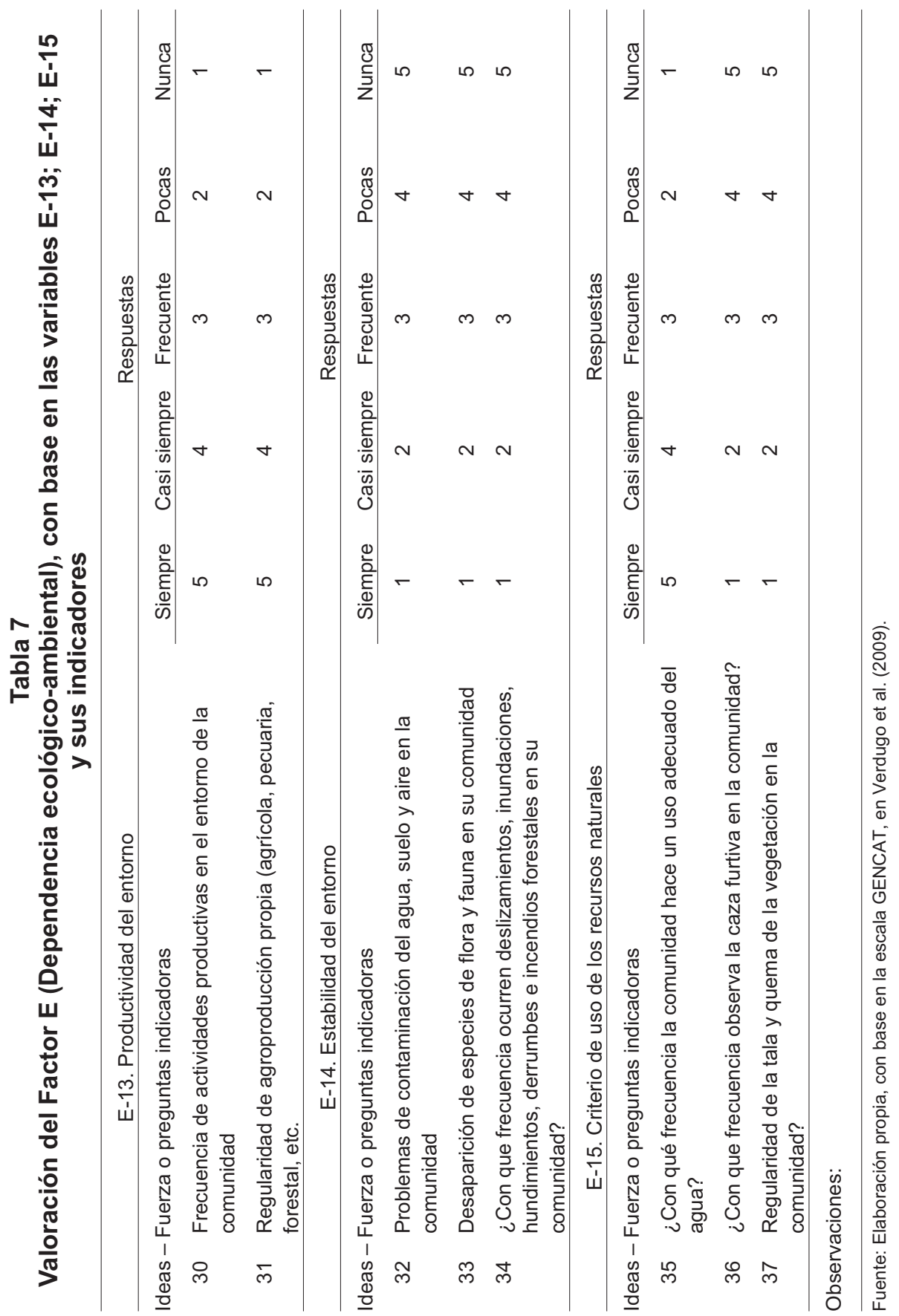




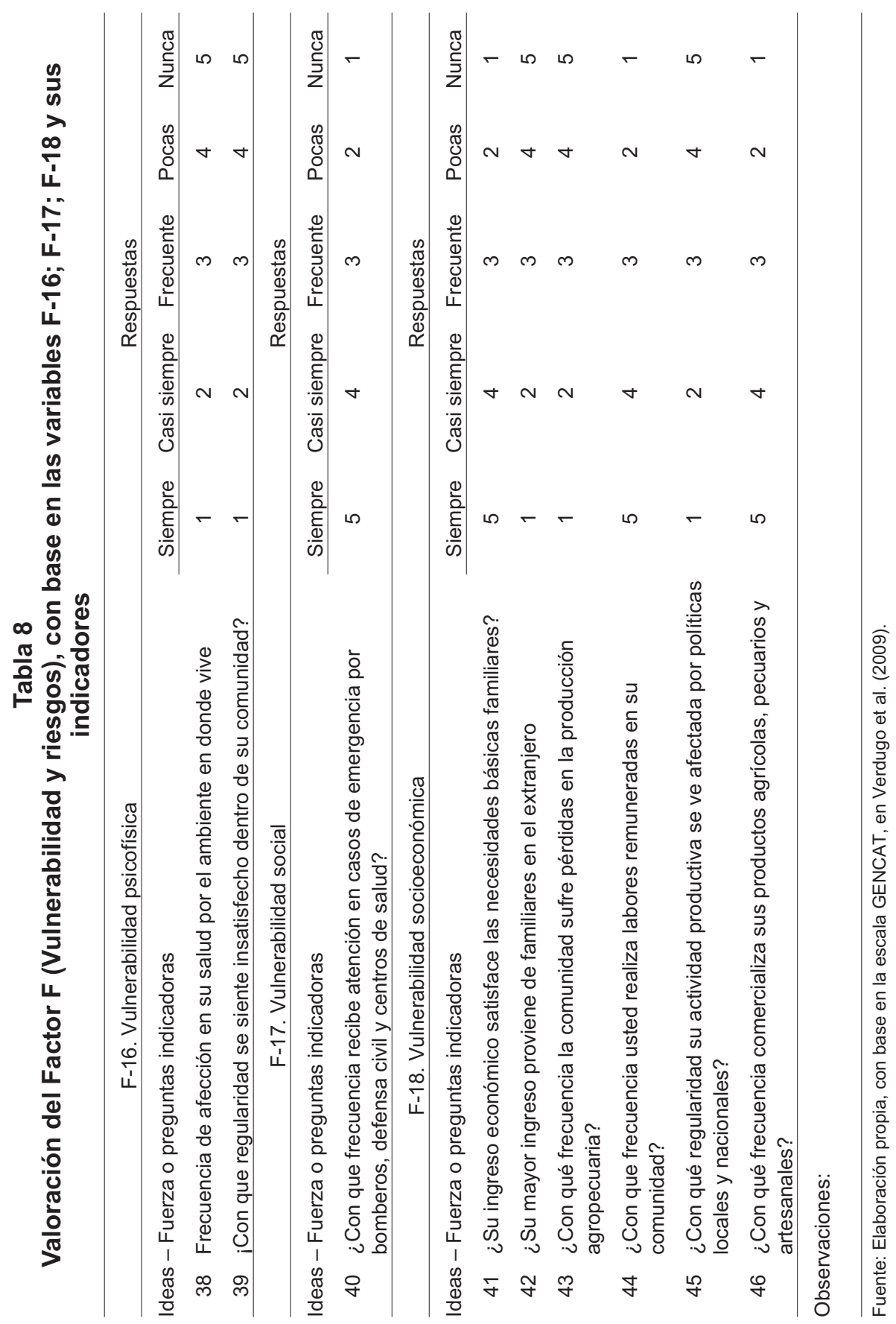




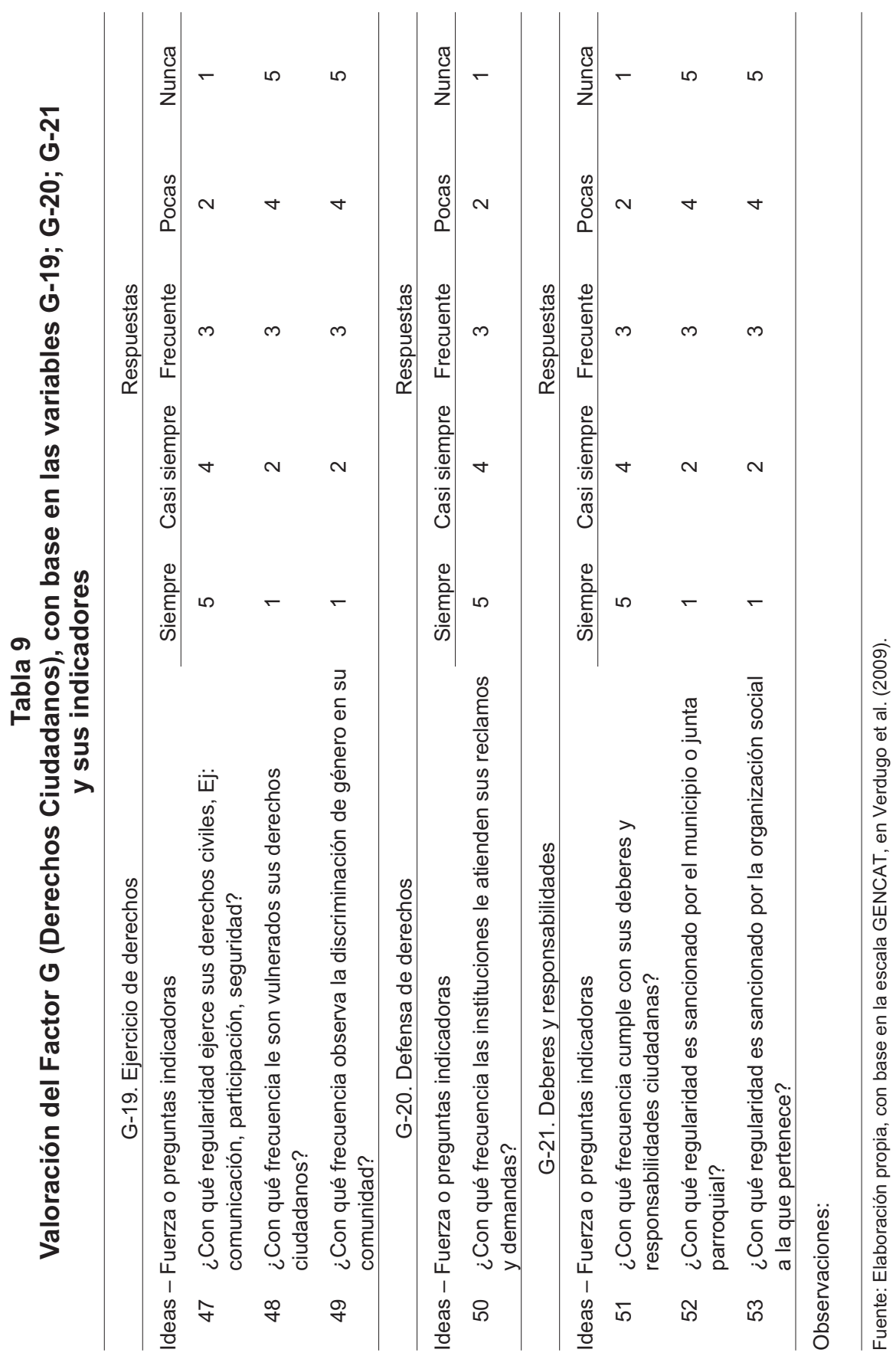


con importantes elementos naturales como son: ríos, quebradas, formaciones naturales y la vegetación existente en ellas, los cuales les otorga un alto valor ambiental y escénico a la subcuenca del río Déleg, mismos que deben ser protegidos.

4.1.2. Mesoclima. Los elementos que definen el mesoclima en la zona de estudio se han mantenido estables en los últimos treinta años, por lo que, no es posible observar variaciones sustanciales en este aspecto. El mesoclima preponderante es el Ecuatorial Mesotérmico Semi-húmedo (600-2.000 m m.). El clima en el cantón Déleg es benigno lo que permite un buen nivel de vida y desarrollo de actividades cotidianas y productivas sin mayores dificultades, no existiendo precipitaciones ni temperaturas extremas que limiten las actividades de la población o afecten negativamente la salud o limiten la producción agropecuaria; sin embargo, la subcuenca exhibe un significativo déficit hídrico que afecta la producción agrícola, haciendo que los rendimientos de los cultivos sean bajos, dependiendo de la mayor o menor presencia de las lluvias.

4.1.3. Recursos hídricos. En el área de estudio la producción y disponibilidad del agua es un problema aún no resuelto satisfactoriamente para los usuarios de este recurso, tanto para consumo humano, riego y abrevaderos, ya que es evidente la escasez del agua en cantidad y calidad, ya por ser de origen superficial está expuesta a las acciones humanas; a esto se suma, la deforestación de la cuenca alta y las descargas de aguas servidas provenientes de las alcantarillas y fosas sépticas.
4.1.4. Suelos. La cobertura edáfica es muy diversa y en virtud de su origen volcánico, son muy susceptibles a la erosión, dependiendo de la pendiente y manejo. Predominan los suelos con epipedones úmbricos (colores oscuros), ácidos; con endopedones de coloración amarillenta a pardo rojizo, con texturas arcillosas, compactos y con presencia de grietas en la época seca, localizados en las áreas bien drenadas. En general, su fertilidad es mediana a baja dado que estos suelos son ácidos, poco profundos y muy susceptibles a la erosión natural y antrópica.

4.1.5. Geología. La litoestratigrafía local que caracteriza al Cantón Déleg contiene en mayor proporción una secuencia de limolitas, lutitas y areniscas finogranulares (Formación Mangán, 34\%); arenas, arcillas, tobas y brechas bien estratificadas, mezcladas con conglomerados (Formación Turí; $6 \%$ ); con aportes volcánicos en un una cobertura de flujos piroclásticos, conglomerados y areniscas de origen volcánico y localmente de avalanchas de escombros (Formación Llacao; 12\%); con áreas sedimentarias originadas por flujos aluviales, coluviales y glaciares (Formaciones Cuaternarias, $20 \%$ ).

4.1.6. Relieve. El Catón Déleg posee casi todas las formas de terreno y geodinámicas propias de una cuenca andina, con una ventaja que el $87 \%$ de la superficie está cubierta por relieves colinados y vertientes cóncavas y convexas, produciendo un patrón topográfico bastante regular. Por el contrario, los terrenos escarpados, característico de los relieves montañosos con vertientes irregulares, representan solamente el $13 \%$. 


\subsubsection{Vulnerabilidad y riesgo. En} función de las características edáficas y litoestratigráficas antes expuestas, se desprende que prácticamente el $98 \%$ del territorio está afectado por alto y mediano riesgo de deslizamientos en masa, lo que hace que la microcuenca sea frágil y baja en estabilidad de los suelos. Las comunidades ubicadas en la zona "roja" o de alto riesgo, deberán seguir las recomendaciones técnicas en cuanto a actividades constructivas, asegurando siempre que cumplan con normas mínimas en materia constructiva para disminuir estos riesgos.

4.1.8. Vegetación. La mayor parte de la vegetación existente está en proceso de degradación, sumada a las condiciones del suelo, la falta de riego y erosión hacen que los cultivos en superficie sean escasos. El asentamiento humano se desarrolla principalmente en la cuenca media; no obstante, se está proyectando hacia la parte alta en donde existen mejores condiciones de suelo y clima, ocasionando que la siembra de pastos avance con gran intensidad, provocando el fraccionamiento del bosque primario, alterando las características hidrológicas de la cuenca alta que por ser más lluviosa permite el desarrollo de la ganadería de leche en regulares condiciones. No existe en la zona ninguna área protegida inscrita en el Sistema Nacional de Áreas Protegidas (SNAP). La fauna la silvestre es muy escasa debido a que la supervivencia está en función de la mayor o menor presencia de la flora y del ser humano. Menos bosques, menos fauna silvestre, ya sea en mamíferos, aves, reptiles, etc.

\subsection{Calidad de vida en las comunidades en estudio y los factores que la determinan}

En la Tabla 10 se muestran los resultados de los Índices de Calidad de Vida (ICV) y los parámetros estadísticos univariados calculados para los siete factores de calidad de vida evaluados en los cuatro sectores antes indicados. Según estos resultados, los sectores de Chini, Nueva Alianza y Bayandel exhiben una buena calidad de vida ya que sus ICV se ubican en el rango de valores entre 8.769 - 16.384 (Tabla 1); por su parte, el sector Déleg tiene una calidad de vida que califica como regular, con tendencia a ser buena, toda vez que su ICV es de 7.427, cercano al límite inferior de la calificación de buena (8.769).

Para determinar los factores que están incidiendo en los valores de los ICV, es necesario analizar los valores promedios obtenidos para dichos factores (columnas A, B, C, D, E, F y G), indicados en la Tabla 10; observándose que para todos los sectores en estudio los factores principales que tienden a deprimir la calidad de vida, corresponde a aquellos cuyos valores medios son menores a 3,5 (considerando la escala entre 1 y 5 con la cual fueron cuantificadas las 53 subvariables indicadoras); es decir, los factores C (Desarrollo cultural) y $F$ (Vulnerabilidad y riesgos).

\subsection{Variables y subvariables que inciden en la calidad de vida en el Cantón Déleg}

En la Tabla 10-1 están resaltados los valores medios inferiores a 3,0; co- 


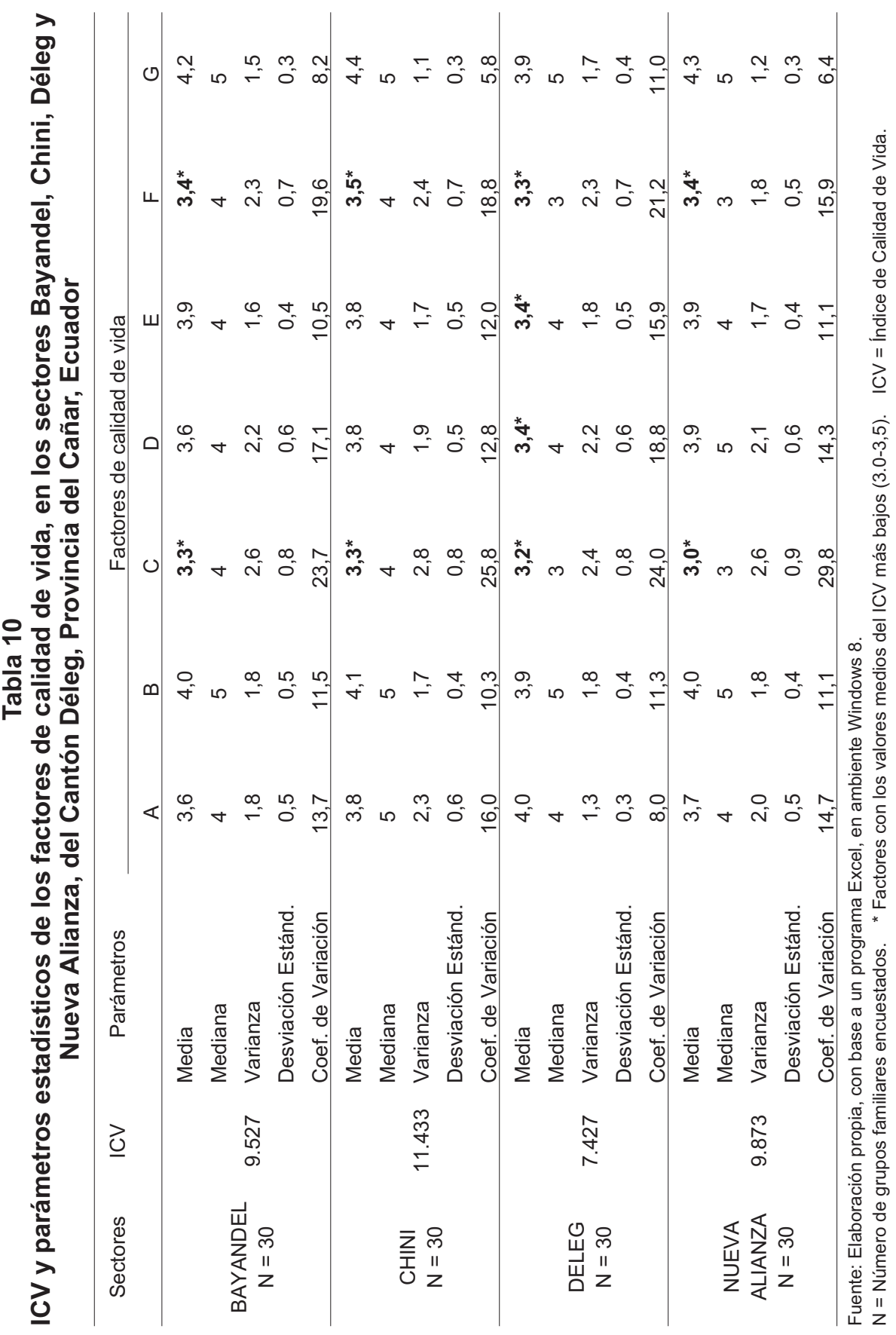




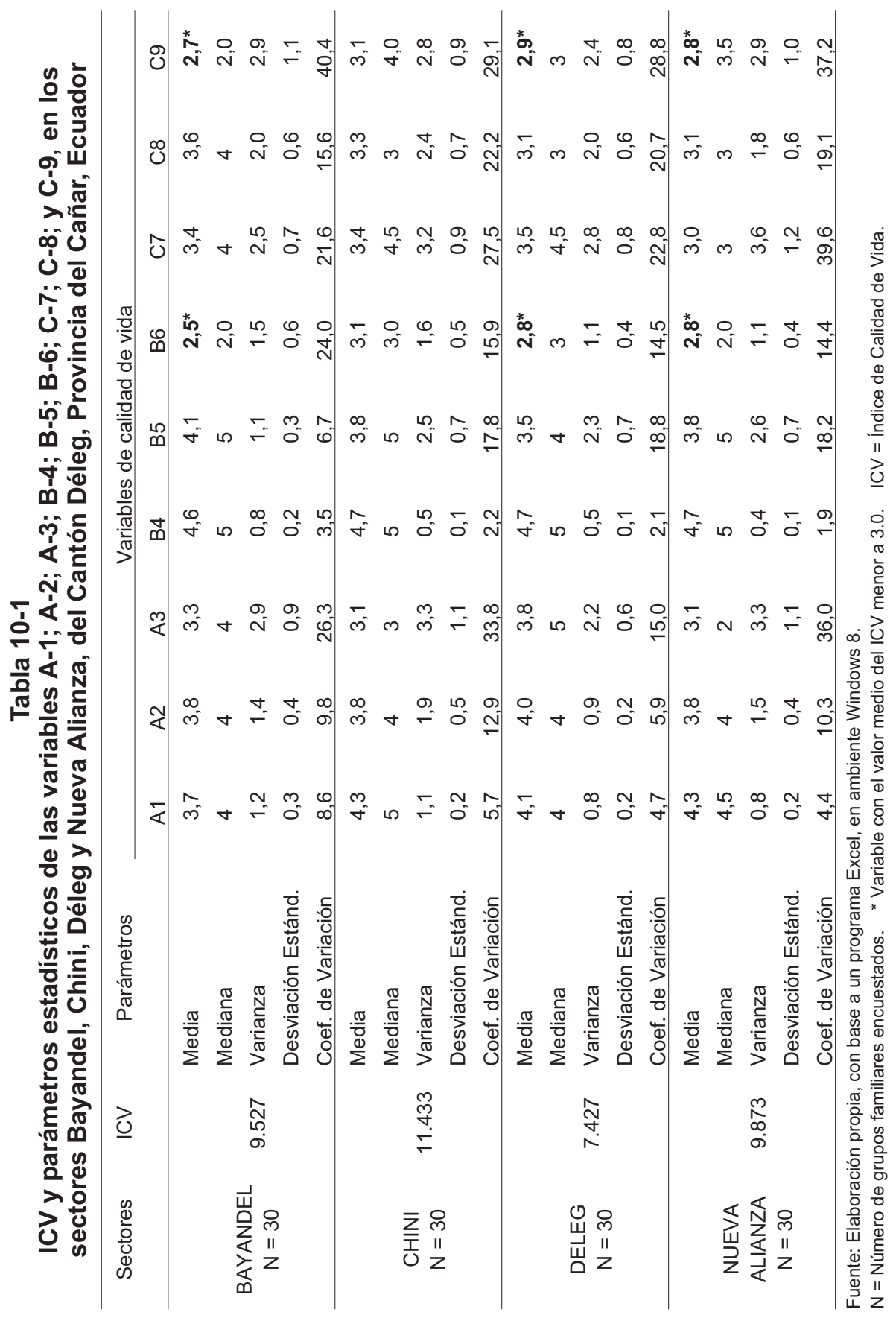


rrespondientes a las variables asociadas con el factores $\mathrm{C}$ ( $\mathrm{C} 9$ = Trabajo adecuado a las aptitudes de la persona) y con el factor B (B6 = Descanso y recreación), variables que mejor explican la reducción de los niveles de calidad de vida en los sectores Bayandel, Déleg y Nueva Alianza; por su parte, en la Tabla 10-2 resalta la variable relacionado con el factor $\mathrm{F}(\mathrm{F} 17=$ Vulnerabilidad social) como la que reduce en forma significativa la calidad de vida en los sectores Bayandel y Déleg.

Las subvariables indicadoras que afectan negativamente la calidad de vida de los sectores en estudio, particularmente las que están relacionadas con los factores $\mathrm{C}$ y $\mathrm{F}$; $\mathrm{y}$ las variables $\mathrm{B} 6$; $\mathrm{C} 9$; $\mathrm{F} 17$ y F18; pueden ser vistas en las Tablas $11-1 ; 11-2 ; 11-3$ y 11-4 las cuales pueden ser precisadas a través de las que tienen menor valor promedio $(<3,0)$; principalmente las que están identificadas como I-15; I-17; I-21; I-26; I-44 e I-46, mismas que tienden a disminuir los valores medios del ICV en todos los sectores en estudio.

\section{4. ¿Cómo se deteriora la calidad de vida en el Cantón Déleg y qué hacer?}

Con base en los resultados resumidos en la Tabla 11-5 es pertinente resaltar los aspectos que más afectan negativamente la calidad de vida en el Cantón Déleg, entre los cuales se incluyen los siguientes: a) El poco tiempo para el disfrute de vacaciones y paseos; b) Escasa capacitación en la comunidad; c) Deficiente aprendizaje personal para ejercer un trabajo adecuado; d) Deficiente control policial de la delincuencia; e) Baja oferta de trabajo remunerado; f) Escasa comercia- lización de la producción agropecuaria y artesanal; g) Escasa participación de las comunidades en actividades socioambientales; $h$ ) Baja frecuencia en el control social de la delincuencia; i) Desaparición de especies de flora y fauna en su comunidad y j) Poca atención de los reclamos, demandas o requerimientos sociales. Además, otros problemas asociados con la alta incidencia de la tala y quema de la vegetación; escaso apoyo del sector público y privado para actividades comunitarias y la escasa atención en casos de emergencia socioambiental por parte de los bomberos, defensa civil y centros de salud, son aspectos que contribuyen a deprimir la calidad de vida en cualquier sector del Cantón Déleg.

Estas deficiencias constituyen retos muy significativos para el gobierno nacional y, en particular, para los gobiernos autónomos descentralizados a nivel regional, ya que pone de manifiesto desequilibrios territoriales que afectan atributos socioeconómicos, socioambientales y ecológico-ambientales los cuales deprimen las condiciones necesarias para un buen vivir; de allí la importancia de resaltar el avance hacia una cultura que permita apreciar, equilibrar y armonizar las relaciones del hombre moderno con los factores y procesos que tienen lugar en la naturaleza con el propósito de que estén encaminadas a garantizar la vida en el futuro.

No obstante, estas carencias también representan oportunidades para que las comunidades se movilicen en función de hacer cumplir las directrices y objetivos incluidos en el Plan de Desarrollo y Ordenamiento Territorial del Cantón Déleg (CONSULCENTRO, 2011), cuyos 


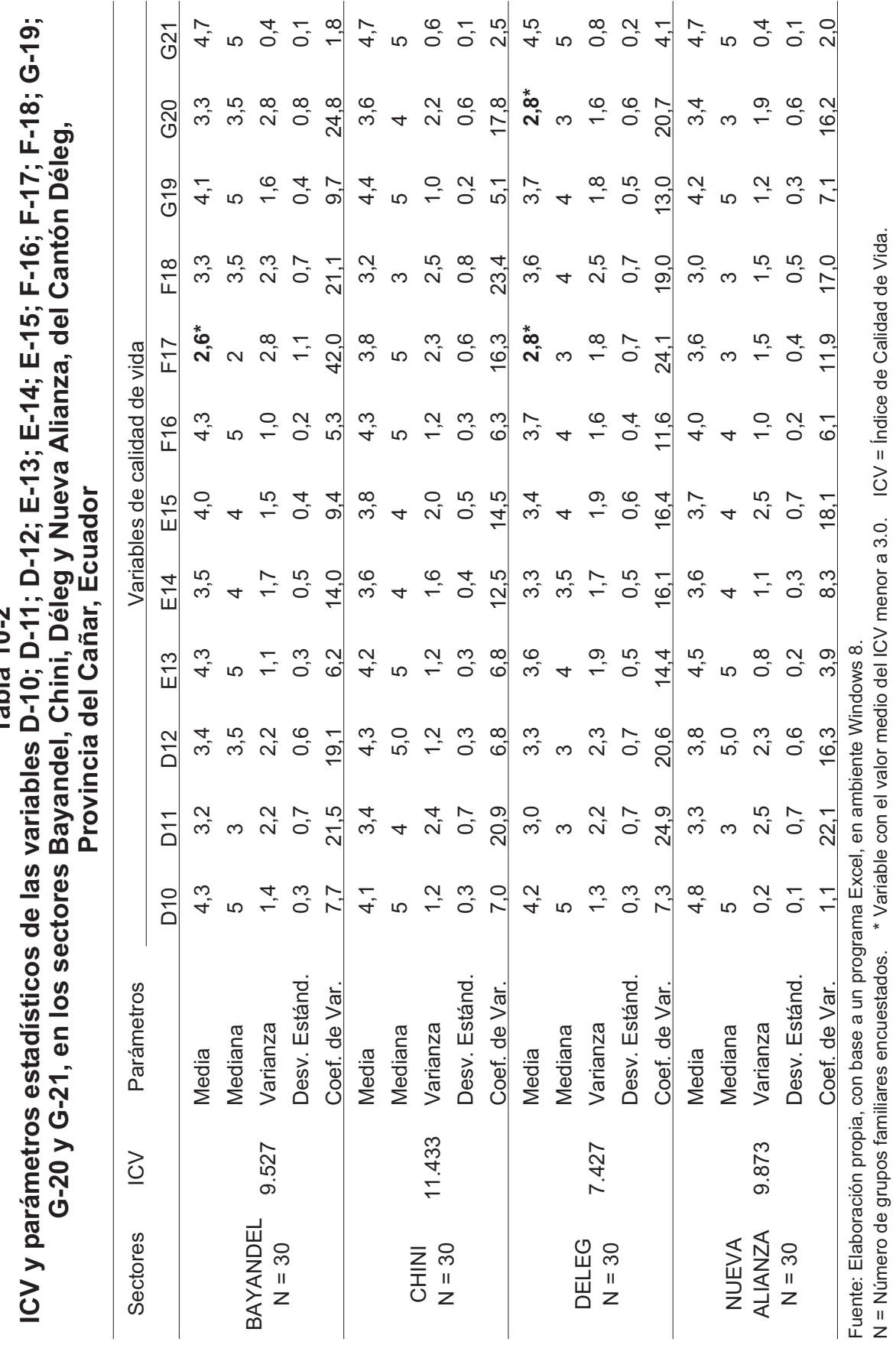


خั่

동

mo

d

은웅

흔

is

$\frac{10}{0}$

ส

(2) N

ए

든 은

웅 훙

임

谷之证

긍휴

บे ब

काष

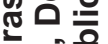

도응흥

듕 웜

츤.

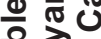

त

㲾

(1)

5)

कि

\&

is is

음음

के

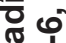

के

ช

ติ

吾

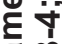

\%

。ำ

$>4$

ㅇ

$\stackrel{\varphi}{\square}$

I.

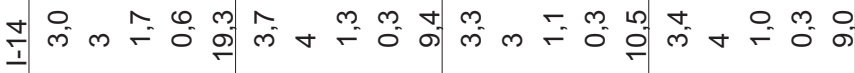

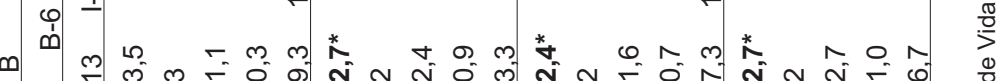

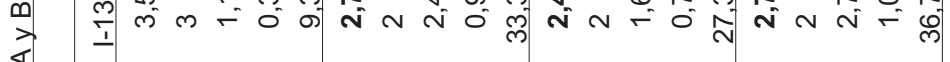

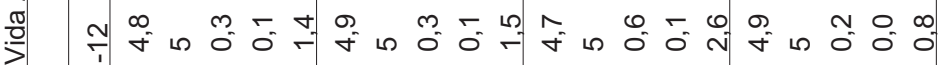

?

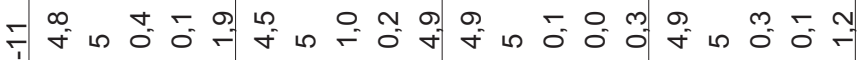

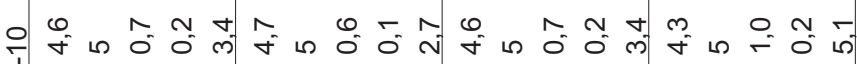

I I

म

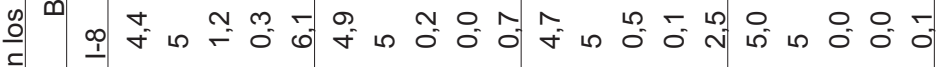

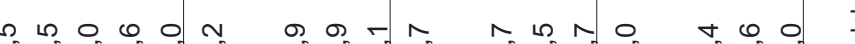
m. m m n

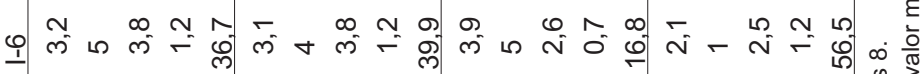

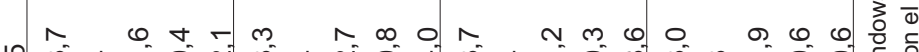

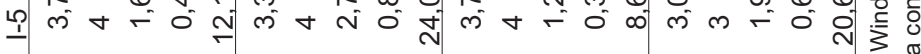

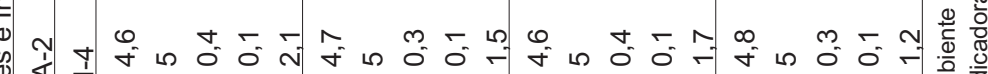
$\frac{1}{0}<1$

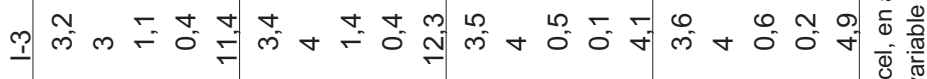
$0 \quad m m n-m \omega m \infty N+0 \wedge N m$

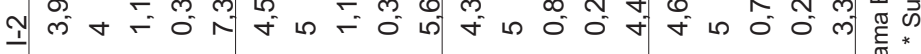
安

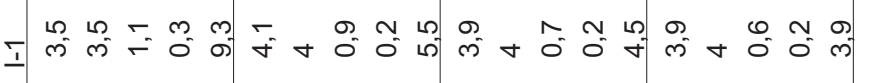

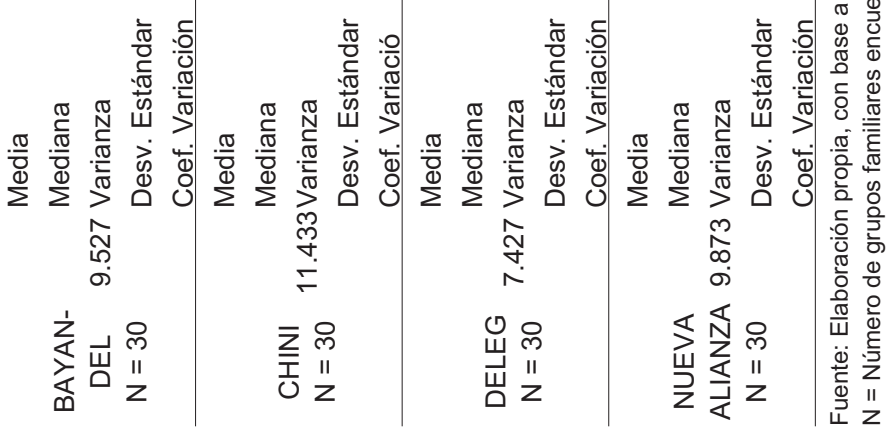




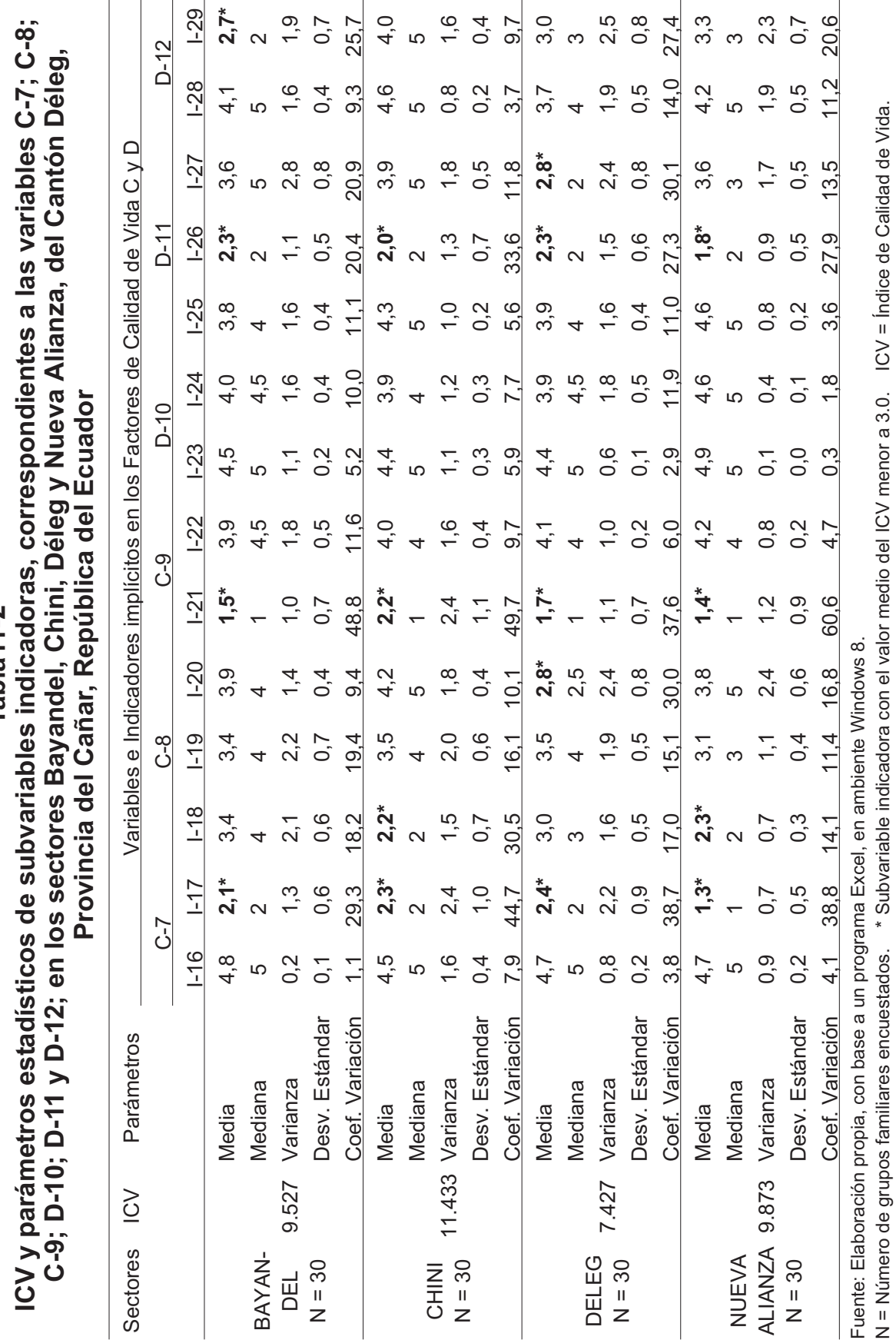




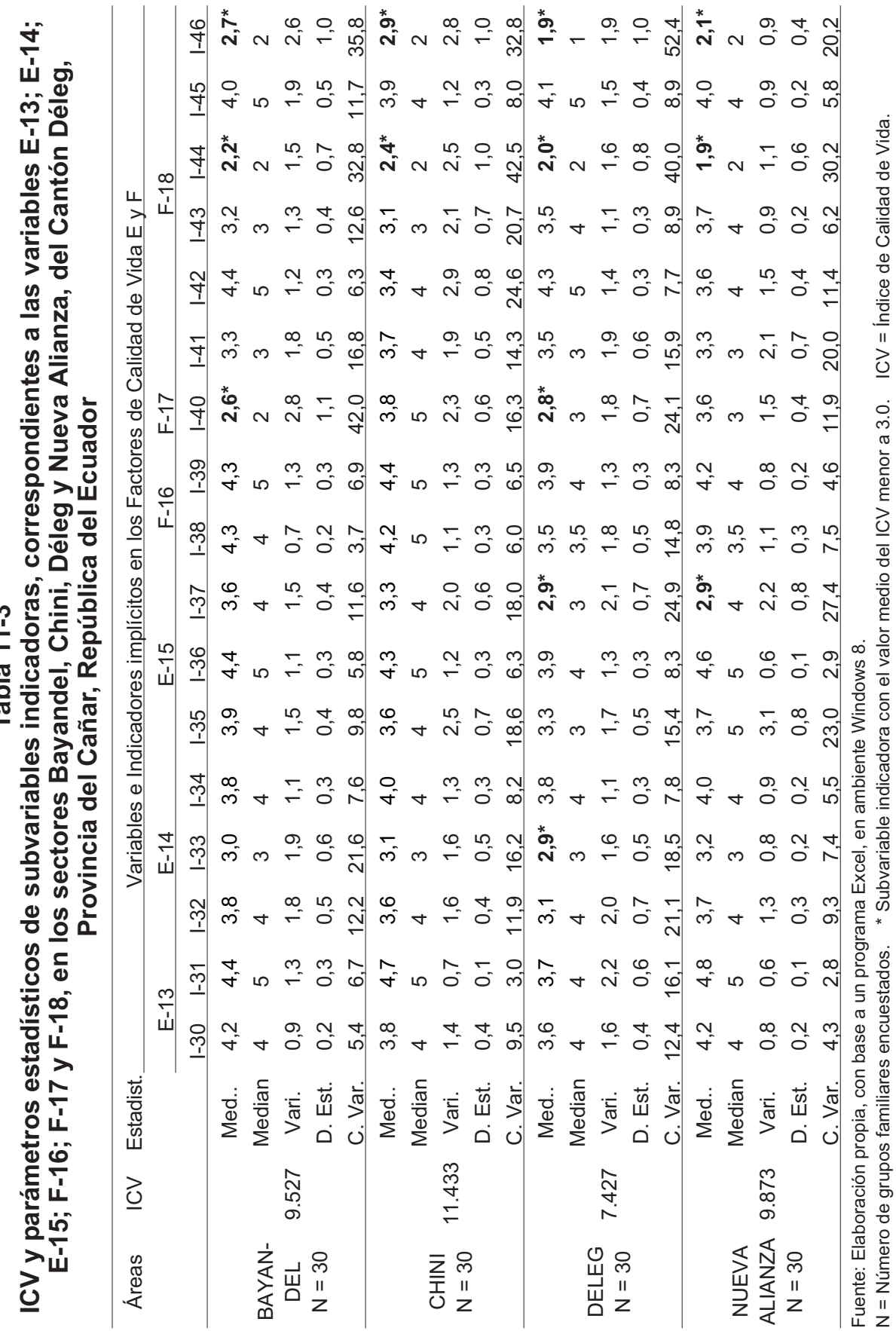




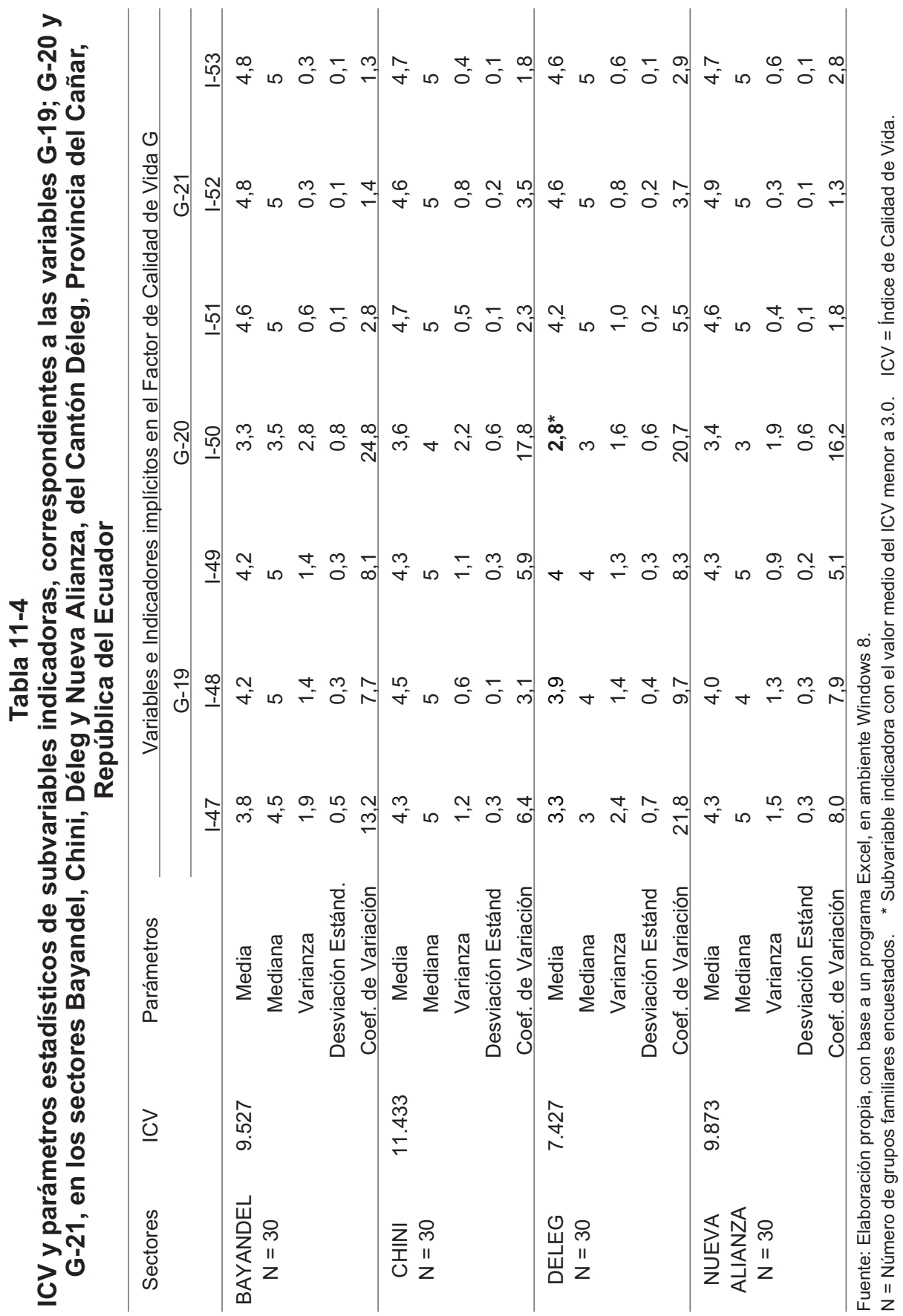




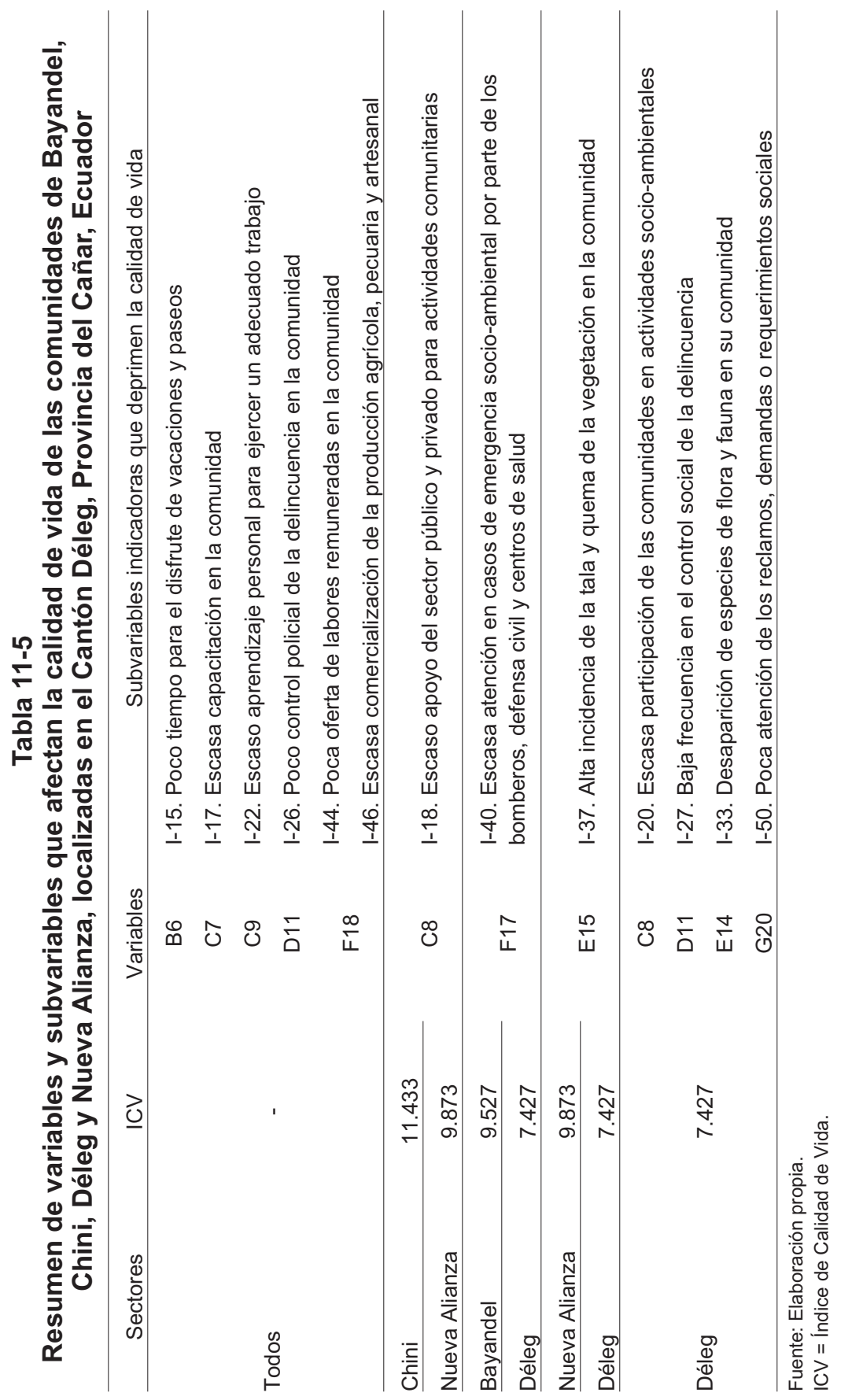


ejes principales son: 1) El desarrollo integral, equilibrado y en términos de calidad de vida; 2) La utilización racional del territorio y gestión responsable de los recursos naturales; 3) La calidad ambiental del territorio y 4) La calidad de la gestión pública y coordinación administrativa.

La síntesis de estas carencias junto con los aspectos institucionales antes puntualizados lo que hacen es destacar aspectos que abarcan desde lo individual hasta lo colectivo, en términos de lo que Hernández (2009) denominó los componentes implícitos en la calidad de vida los cuales, manejados adecuadamente, potenciarían las oportunidades institucionales y las fortalezas comunitarias para mejorar o mantener buenas condiciones de vida humana; esto es:

A. Calidad Ambiental (mejoramiento de la infraestructura de las viviendas respecto a su entorno; desarrollo del sentido de pertenencia por parte de la comunidad en relación con el territorio donde habita y percepción de su impacto socioambiental);

B. Bienestar (oferta de empleos de calidad, dotación de servicios y espacios libres, accesibilidad a bienes y servicios económicos) y

C. Identidad (apropiación del territorio a través del tiempo disponible, participación en la producción del entorno, relaciones sociales y asociacionismo, derechos políticos y ciudadanos).

Los aspectos antes puntualizados permiten destacar los elementos, factores y procesos-respuesta que son fundamentales a la hora de valorar la calidad de vida de un sitio en particular $y$, sobretodo, las acciones que deben realizar en conjunto el Gobierno Autónomo Descentrali- zado del Canto Déleg y las comunidades organizadas en Juntas de Agua localizadas en los sectores de Bayandel, Chini, Déleg y Nueva Alianza, con la finalidad de mejorar su calidad de vida; haciendo la salvedad que la solución para equilibrar y mejorar la calidad de vida no está solo en el desarrollo de planes y políticas de Estado que provean alimento y seguridad para todos, la solución va mucho más allá de lo meramente estructural; hay mucho de cultura ciudadana, respeto al ambiente, convivencia en colectivo y amor por el Planeta.

\section{Conclusiones}

El modelo factorial del Índice de Calidad de Vida (ICV) utilizado para evaluar los niveles de calidad de vida en la subcuenca del río Déleg, en particular de los sectores Bayandel, Chini, Déleg y Nueva Alianza, fue el adecuado ya que permitió valorar un número de factores, variables y subvariables indicadoras que fue suficiente para medir el nivel de vida en dichos sectores, que en general es buena, particularmente para los sectores medio y alto de la subcuenca, porque el valor promedio del ICV se ubicó en el rango de 16.384 a 8.769 ; principalmente para los sectores de Chini, Nueva Alianza y Bayandel; por el contrario, el sector Déleg tiene una calidad de vida que califica como regular, con tendencia a ser buena, toda vez que su ICV es de 7.131

La información contenida en este trabajo será de utilidad para el Gobierno Autónomo Descentralizado (GAD) del Cantón de Déleg, y a las mismas comunidades que habitan en los sectores de Bayandel, Chini, Déleg y Nueva Alianza, 
porque permitirá aunar esfuerzos para llevar adelante políticas públicas y acciones comunitarias dirigidas a mejorar la calidad de vida de la gente que vive en dicho Cantón, principalmente en los sectores antes mencionados.

En este sentido, teniendo como referencia las precisiones teóricas y metodológicas analizadas en el contexto de esta investigación, se recomienda que el GAD de Déleg continúe con este estudio, extendiéndolo hacia otras comunidades localizadas en la parte baja de la subcuenca del río Déleg, teniendo como apoyo metodológico el modelo del Índice de Calidad de Vida (ICV) aplicado en este trabajo; lo cual permitiría llevar a cabo una validación del mismo con el propósito de mejorar su robustez técnica y científica.

Por otra parte, es conveniente realizar la operacionalización de los factores, variables y subvariables indicadoras del modelo del ICV, con el objetivo de reducir su estructura, principalmente en el número de subvariables indicadoras, lo cual mejorará su alcance predictivo y consistencia estadística.

\section{Referencias bibliográficas}

Ardila, Rubén (2003), Calidad de vida: una definición integradora. Revista Latinoamericana de Psicología, vol. 35, núm. 2, Fundación Universitaria Konrad Lorenz, pp. 161-164. Disponible en: http://www.redalyc.org/articulo.oa ?id=80535203. (Consultado el 2411-2015)

CONSULCENTRO (2011), Plan de Desarrollo y Ordenamiento Territorial del Cantón Déleg y Actualización del Plan de Ordenamiento Territorial del Centro Ur- bano. Resumen Ejecutivo y Tomo I.

163 p. Disponible en: http://www.gadmunicipaldeleg.gob.ec/gadmunicipaldeleg/index.php/municipio/pdyot (Consultado el 15-09-2015)

Contreras, Manfredi Hernán y América Cordero. (1994), Ambiente, Desarrollo Sustentable y Calidad de Vida. Caracas, Venezuela. $269 \mathrm{p}$.

Córdoba, Rafael Cejudo. (2007), Capacidades y Libertad. Una Aproximación a La Teoría de Amartya Sen. Revista Internacional De Sociología. Vol. 65, $N^{\circ} 47$, Mayo-Agosto. Universidad de Cordoba, España, 9-22, Disponible en: http://revintsociologia.revistas. csic.es/index.php/revintsociologia/article/view/50/50. (Consultado el 2002-2015)

Da Conceiòáo de Almeida María (2008), Para comprender la complejidad. Primera edición. Hermosillo, Sonora. México. 62 p. Disponible en: http://moodle2.unid.edu.mx/dts_cursos_mdl/lic/ E/ACEC/AM/05/Para_comprender. pdf (Consultado el 24-03-2015)

González, Dipsy (2012), Calidad de Vida en la Comunidad Ribereña del Orinoco Las Galderas. Universidad Nacional Experimental de Guyana (UNEG). Disponible en: http://www.cidar.uneg. edu.ve/DB/bcuneg/EDOCS/TESIS/ TRABAJOS_DE_ASCENSOS/ TASHTG65852012DipsyGonzalez.pdf. (Consultado el 06-07-2015)

Hernández, Agustín (2009), Calidad de vida y medio ambiente urbano. Indicadores locales de sostenibilidad y calidad de vida urbana. Revista INVI Vol.24. N ${ }^{\circ}$ 65. Santiago, pp: 79-11. Disponible en: http://www.scielo.cl/scielo.php? script=sci_arttext\&pid=S0718-8358 2009000100003. (Consultado el 1501-2016)

Lovelock, James (2007), La venganza de la tierra. La teoría de GAIA y el futuro de la humanidad. Editorial Planeta. 
Traducción al español por Mar García Puig. Barcelona, España. 249 p.

Palella, Santa y Feliberto. Martins (2006). Metodología de la investigación cuantitativa. Editorial FEDUPEL, Caracas. Venezuela. $253 p$.

Palomba Rosella (2002), Calidad de Vida: Conceptos y medidas. Institute of Population Research and Social Policies. Roma, Italia. Disponible en: http://www.cepal.org/celade/agenda /2/10592/envejecimientorp1_ppt.pdf. (Consultado el 26-02-2015).

Papa Francisco (2015), Carta encíclica laudato si' del Santo Padre Francisco sobre el cuidado de la casa común. Encíclica $\mathbf{N}^{\circ}$ 18. Capítulo primero. Lo que está pasando a nuestra casa. pag. 17. Disponible en: http://www.javeriana.edu.co/documents/15832/5510 469/laudato+si.pdf (Consultado el 20-06-2015)

Raymundo Mariela y Edgar Jaimes (2015), Modelo para valorar la Calidad de Vida de los egresados del programa nacional de aprendizaje del INCES, estado Cojedes. Revista AGROLLANÏA. Vol. 12 / Enero-Diciembre. UNELLEZ / VIPI / Postgrado, pp: 7074. Disponible en: http://www.post- gradovipi.50webs.com/archivos/agrollania/2015/agro13.pdf

Suarez, Román Mayo; Soriano Ramón Robles y Gómez López José (2005), Efectos de las Microempresas en la Calidad de Vida de Mujeres en Comunidades Rurales Pobres. Disponible en: http:// www.ciriec-uaconference.org/images /upload/pdf/PAPERS/87_SUAREZESCRITO\%20LARGO_txt.pdf (Consultado el 09-04-2015).

Urbina, Verónica (2012), Análisis del Concepto de Calidad de Vida y su relación con el Socialismo del Siglo XXI. Disponible en: http://www.aporrea.org/ideologia/ a144673.html. Creado. Miércoles, 06/06/2012 05:40. Consultado el 30/03/2015.

Verdugo, Miguel Ángel; Benito Arias Martínez; Laura. E. Gómez Sánchez y Robert L. Shalock. (2009), Escala GENCAT. Manual de aplicación de la Escala GENCAT de Calidad de Vida. Departamento de Acción Social y Ciudadanía de la Generalitat de Catalunya. España.80 p. Disponible en: http://inico.usal.es/documentos/EscalaGencatManualCAST.pdf. Consultado el 09-04-2015. 